\title{
Evaluation of Efficacy of Anionic Surfactant Degradation in the Presence of Concomitant Impurities of Natural Waters
}

\author{
Yuliya Shvadchina, Vera Vakulenko, Elena Alekseenko, and Anatoliy Sova \\ A.V. Dumansky Institute of Colloid Chemistry andWater Chemistry, National Academy of Sciences of Ukraine, \\ 42 Vernadsky blvd., 03680 Kyiv-142, Ukraine
}

Correspondence should be addressed to Vera Vakulenko; vakulvera@ukr.net

Received 31 May 2013; Accepted 3 August 2013

Academic Editor: Oleksandr A. Loboda

Copyright (C) 2013 Yuliya Shvadchina et al. This is an open access article distributed under the Creative Commons Attribution License, which permits unrestricted use, distribution, and reproduction in any medium, provided the original work is properly cited.

\begin{abstract}
The efficacy of anionic surfactant-sodium alkylbenzene sulfonate (ABS) degradation in the river waters and model solutions containing humic acid by various oxidation processes has been compared. The most effective method is photocatalytic ozonation $\left(\mathrm{O}_{3} / \mathrm{TiO}_{2} / \mathrm{UV}\right)$ which ensures maximum reduction of $\mathrm{ABS}$ concentration (94\%-95\% over 20-30 min) from $\sim 5 \mathrm{mg} / \mathrm{dm}^{3}$ to values not exceeding the MPC $\left(<0.5 \mathrm{mg} / \mathrm{dm}^{3}\right)$ and the highest degree of total organic carbon (TOC) removal (up to $\left.74 \%\right)$ at the lowest values of specific ozone consumption per $1 \mathrm{mg} / \mathrm{dm}^{3}$ of TOC compared to ozonation and $\mathrm{O}_{3} / \mathrm{UV}$. Photocatalytic oxidation with air oxygen $\left(\mathrm{O}_{2} / \mathrm{TiO}_{2} / \mathrm{UV}\right)$ and $\mathrm{O}_{3} / \mathrm{UV}$ treatment provides a smaller decrease in ABS concentrations (86\%-93\% and $71 \%-87 \%$ within 20-30 min, resp.) and significantly lowers TOC removal (up to $57 \%$ and $47 \%$, resp.). Ozonation and UV irradiation, used separately, are inefficient methods for ABS degradation $(<40 \%)$, and for TOC removal $(<15 \%)$.
\end{abstract}

\section{Introduction}

Synthetic surface-active substances (SAS), due to the wide application in industry and household and shortcomings of existing methods of wastewater treatment, find their way into natural waters [1-3] and have a negative impact on the environment and aquatic biota [1]. Different types of anionic, nonionic, and cationic surfactants have been detected in sewage effluents with concentrations up to 1090 , 332 , and $62 \mu \mathrm{g} / \mathrm{dm}^{3}$, respectively [1]. The concentrations of SAS in river waters depend upon a percent removal at the sewage treatment plants (STPs), sorption, solids settling, and degradation in stream. Linear alkylbenzene sulfonates (LAS) have been reported in surface waters at concentrations up to $416 \mu \mathrm{g} / \mathrm{dm}^{3}$ [1]. Very low concentration $\left(<0.1 \mathrm{mg} / \mathrm{dm}^{3}\right)$ of LAS is discharged in rivers after aerobic STPs such as activated sludge process or trickling filter. Higher concentrations of anionic surfactants $\left(0.36-0.49 \mathrm{mg} / \mathrm{dm}^{3}\right)$ were predicted in the Hindon River (India) from up flow anaerobic based STPs [2]. The average annual concentrations of anionic surfactants in the waters of the Dnieper River and some of its tributaries $\left(0.07-0.11 \mathrm{mg} / \mathrm{dm}^{3}\right.$ and $0.21-0.32 \mathrm{mg} / \mathrm{dm}^{3}$, resp.
[3]) were below the maximum permissible concentration $\left(\mathrm{MPC}=0.5 \mathrm{mg} / \mathrm{dm}^{3}[4]\right)$, but their content in some samples exceeded the MPC by a factor of 1.5-2. In a shallow urban stream receiving untreated household wastewaters, LAS were found between 0.43 and $1.9 \mathrm{mg} / \mathrm{dm}^{3}$ [5]. Strongly polar metabolic intermediates of LAS - sulfophenyl carboxylates were detected in river water $\left(14-155 \mu \mathrm{g} / \mathrm{dm}^{3}\right)$ and in drinking water $\left(1.6-3.3 \mu \mathrm{g} / \mathrm{dm}^{3}\right)$ [6]. Some types of surfactants and their metabolites are compounds with estrogenic activity known as endocrine disrupting chemicals (EDCs) [7]. So reliable removal of surfactants from the real water systems is an important ecological task, and complex composition of organic and inorganic substances in natural and wastewaters and the processes occurring in them must be taken into account.

The major organic impurities in surface waters-humic and fulvic acids (HA and FA) can fix organic xenobiotics (e.g., pesticides, petroleum products, surfactants, etc.) through different mechanisms, through formation of strong chemical bonds (such as ionic, hydrogen, and covalent), charge transfer or weak interactions (such as van der Waals forces, ligand exchange, hydrophobic links) [8-11]; therefore, 
they may significantly affect the properties and behavior of xenobiotics in the processes of natural water or sewage treatment $[12,13]$. In particular, $\mathrm{HA}$ are able to bind anionic surfactants (ASAS) through hydrophobic interactions, significantly distorting their quantification by standard extractionphotometric method with methylene blue $[8,14]$. The binding of surfactants with mentioned natural organic matter (NOM) depends on the structure of the substrate and NOM and a number of other factors (such as $\mathrm{pH}$, ionic strength, and duration of exposure) $[8,10,11]$. It was shown that HA have a greater affinity for binding surfactants and other xenobiotics than less hydrophobic FA [8-10, 13].

Therefore, the HA and FA, along with some inorganic ions, affect the kinetics, mechanism, content of intermediate products, the degree of organic xenobiotics detoxification, and decomposition in natural and wastewater by photolytic and oxidation methods $[12,13,15-23]$. The degree of degradation of xenobiotics $[24,25]$ and specific consumption of oxidizer [18] greatly depend on the qualitative composition of organic impurities of water matrix and their total concentration. In low concentrations (up to $3 \mathrm{mg} / \mathrm{dm}^{3}$ as dissolved organic carbon (DOC)) HA and FA can sensitize photolytic degradation of certain organic xenobiotics $[20,26]$ as well as initiate a decomposition of ozone molecules resulting in the hydroxyl radicals generation, which accelerate the oxidation of resistant impurities [12]. For example, the destruction of sodium dodecylbenzene sulfonate (ASAS) under ozonation or catalytic ozonation of the solution $\left(C_{0}=0.028 \mathrm{mmol} / \mathrm{dm}^{3}\right.$, $\mathrm{pH} 7$ ) in the presence of $1 \mathrm{mg} / \mathrm{dm}^{3} \mathrm{HA}$ was accelerated 1.7 times [12]. $\mathrm{HA}$ and $\mathrm{Fe}^{3+}$ ions have a synergistic effect on photolytic degradation of 4-n-nonylphenol (metabolite of nonionic SAS (NSAS) related to EDCs) [26]. In the presence of HA ( $1 \mathrm{mg} / \mathrm{dm}^{3}$ as DOC) and $2 \mathrm{mg} / \mathrm{dm}^{3} \mathrm{Fe}^{3+}$ the duration of irradiation $(\lambda>300 \mathrm{~nm})$ needed for reduction of initial concentration of 4- $n$-nonylphenol $\left(C_{0}=2 \mathrm{mg} / \mathrm{dm}^{3}\right)$ by $96 \%$ 97\% declined 9.5 times (from 19 to 2 hours).

However, according to $[17,21]$ rate constants of photolytic and photocatalytic $\left(\mathrm{O}_{2} / \mathrm{TiO}_{2} / \mathrm{UV}\right)$ degradation of some other xenobiotics in the presence of even a little amount of NOM $\left(0.5-1 \mathrm{mg} / \mathrm{dm}^{3}\right.$ as DOC) were decreased by $25 \%-57 \%$. HA and FA at elevated concentrations are powerful scavengers of ${ }^{\circ} \mathrm{OH}$ radicals and retard the chemical and photocatalytic degradation of resistant xenobiotics in natural and wastewaters $[13,15-20,23]$. For example, in the presence of $30 \mathrm{mg} / \mathrm{dm}^{3}$ FA or HA (DOC $\sim 16 \mathrm{mg} / \mathrm{dm}^{3}$ ), rate constants of oxidation of some aromatic hydrocarbons by Fenton reagent $\left(\mathrm{Fe}^{2+} / \mathrm{H}_{2} \mathrm{O}_{2}\right)$ were decreased by $45 \%-90 \%$ [13]. Photocatalytic degradation of some synthetic compounds at high concentrations of HA or NOM was retarded 2-10 times [16, 17, 24, 25].

Nevertheless, analysis of published works $[12,13,15-18$, $22,24-26$ indicates that various catalytic and photocatalytic processes are promising methods of destruction of resistant organic xenobiotics, even if they are present in a complex matrix of natural and wastewaters. However, the rate of xenobiotics oxidation in real waters is considerably reduced. Therefore, higher concentrations or doses of oxidizers $[15,18]$ and longer treatment time [25] are required for their effective destruction.
The degree of destruction of surfactants and their metabolites by various methods in real waters currently has not been researched thoroughly $[12,22,25]$. According to [22] a concentration of two NSAS (Tergitol and Triton $\mathrm{X}-100)$ during photochemical oxidation $\left(\mathrm{H}_{2} \mathrm{O}_{2} / \mathrm{UV}, \mathrm{C}_{\mathrm{H}_{2} \mathrm{O}_{2}}\right.$ $\left.=600 \mu \mathrm{mol} / \mathrm{dm}^{3}, \lambda=254 \mathrm{~nm}\right)$ of their model solutions in distilled water $\left(C_{0}=5 \mu \mathrm{mol} / \mathrm{dm}^{3}, \mathrm{pH}\right.$ 6.7-6.9) was reduced by $97 \%$ within $10 \mathrm{~min}$, whereas in tap water, purified wastewater and untreated wastewater (DOC-0.7, 3.5 and $22-27 \mathrm{mg} / \mathrm{dm}^{3}$, resp.), only by $73 \%-76 \%$, $58 \%-$ $62 \%$, and $12 \%-15 \%$, respectively. The oxidation of model NSAS solutions with photo-Fenton $\left(\mathrm{H}_{2} \mathrm{O}_{2} / \mathrm{Fe}^{2+} / \mathrm{UV}\right)$ also provided a reduction of their concentration by $94 \%-96 \%$ within $10 \mathrm{~min}$ at a lesser concentration of oxidizing agent $\left(\mathrm{C}_{\mathrm{H}_{2} \mathrm{O}_{2}}=100 \mu \mathrm{mol} / \mathrm{dm}^{3}, C_{\mathrm{Fe}^{2+}}=25 \mu \mathrm{mol} / \mathrm{dm}^{3}, \lambda=254 \mathrm{~nm}\right)$. However, the NSAS removal from tap, purified wastewater and untreated wastewater using the mentioned method was decreased to $60 \%-64 \%, 24 \%-35 \%$, and $12 \%-25 \%$ over $10 \mathrm{~min}$, respectively [22].

The purpose of this work was to define the most efficient method of destruction of anionic surfactants in the presence of HA and NOM of river waters.

\section{Materials and Methods}

As objects of the research we used sodium alkylbenzene sulfonate (ABS) of the averaged composition $\mathrm{C}_{12} \mathrm{H}_{25}-\mathrm{C}_{6} \mathrm{H}_{4}$ $\mathrm{SO}_{3} \mathrm{Na}$, commercial humic acid from Fluka Co. (elemental composition (\%): $\mathrm{C}-46.63, \mathrm{H}-4.3, \mathrm{~N}-0.72$, ash content 20), and the Dnieper and Desna Rivers waters, sampled in winter and summer seasons, as well as a sample of fulvic acid separated from the Dnieper River water (elemental composition (\%): $\mathrm{C}-36.8, \mathrm{H}-3.9, \mathrm{O}-56.2, \mathrm{~N}-1.2$, and $\mathrm{S}-$ 1.9). Humic acid from Fluka Co. consists mainly of high molecular weight (MW) fractions (content of fractions with MW $>50 \mathrm{kDa}$ is $\sim 95 \%$ ) [27]. The fractions of compounds with MW up to $10 \mathrm{kDa}$ are dominant in NOM of the Dnieper River water with MW of main fraction- $0.5-1 \mathrm{kDa}$ $[28,29]$. The river waters contain mainly fulvic acids whose contents are $\sim 20-40$ times as high as those of humic acids. Characteristics of model solutions of ABS, HA, FA, and river waters are listed in Table 1.

Commercial $\mathrm{TiO}_{2}$ Degussa P-25 (81\% of anatase, $19 \%$ of rutile; $S_{\mathrm{BÈT}}=56 \mathrm{~m}^{2} / \mathrm{g}$, size of particles $\sim 30 \mathrm{~nm}$ ) [30] was used as a photocatalyst at a concentration of $0.5 \mathrm{~g} / \mathrm{dm}^{3}$.

Model solutions in distilled water containing ABS and HA simultaneously and separately at initial concentrations $5 \mathrm{mg} / \mathrm{dm}^{3}$ and $10 \mathrm{mg} / \mathrm{dm}^{3}$, respectively, as well as river waters and solutions of $\mathrm{ABS}\left(\mathrm{C}_{0}-5 \mathrm{mg} / \mathrm{dm}^{3}\right)$ in river waters sampled in winter, were oxidized by various methods $\left(\mathrm{O}_{3}, \mathrm{O}_{3} / \mathrm{UV}\right.$, $\mathrm{O}_{3} / \mathrm{TiO}_{2} / \mathrm{UV}, \mathrm{O}_{2} / \mathrm{TiO}_{2} / \mathrm{UV}$, and $\left.\mathrm{O}_{2} / \mathrm{UV}\right)$ at room temperature $\left(18 \pm 2^{\circ} \mathrm{C}\right)$ on a laboratory facility equipped with a computer system of recording of ozonation parameters [31], in a quartz reactor $\left(d=3.6 \mathrm{~cm}, V=0.44 \mathrm{dm}^{3}\right)$ equipped with a dispenser at the bottom for feeding an ozone-air mixture (OAM) or air, spherical defoamer $\left(V \sim 1 \mathrm{dm}^{3}\right)$ at the top and peristaltic pump for ensuring slurry circulation from bottom 
TABLE 1: Characteristics of initial solutions of ABS, humic, or fulvic acids and river waters.

\begin{tabular}{|c|c|c|c|c|c|}
\hline Object of research & $\begin{array}{c}\text { Colour value, } \\
\text { degr. }\end{array}$ & $A_{254}, \mathrm{~cm}^{-1}$ & TOC, $\mathrm{mg} / \mathrm{dm}^{3}$ & $\mathrm{pH}$ & $\begin{array}{c}\text { Concentration } \\
\text { of } \mathrm{HCO}_{3}^{-}, \\
\text {mg-eq/dm }{ }^{3}\end{array}$ \\
\hline ABS solution in distilled water & - & 0.04 & 3.6 & 5.7 & 0 \\
\hline HA solution in distilled water & 68 & 0.35 & 3.8 & 7.2 & 0 \\
\hline ABS and HA solution in distilled water ( $t=0$ or 14 days) & $67-71$ & $0.34-0.39$ & $6.1-6.3$ & 7.2 & 0 \\
\hline Desna River water (winter) & 18 & 0.22 & 7.6 & 8.0 & 3.7 \\
\hline Solution of ABS in the Desna water (winter) & 24 & 0.27 & 9.4 & 8.2 & 3.7 \\
\hline Dnieper River water (winter) & 38 & 0.38 & 12.4 & 7.9 & 3.1 \\
\hline Solution of ABS in the Dnieper water (winter) & 38 & 0.42 & 16.1 & 7.8 & 3.1 \\
\hline Dnieper River water (summer) & 43 & 0.43 & 17.9 & 8.3 & 2.75 \\
\hline Desna River water (summer) & 30 & 0.27 & 14.7 & 8.6 & 3.7 \\
\hline Solution of FA in model water & 72 & 0.60 & 16.4 & 8.2 & 2.0 \\
\hline Solution of FA in distilled water & 58 & 0.54 & 15.8 & 6.0 & 0 \\
\hline
\end{tabular}

Note: Initial concentration of ABS and $\mathrm{HA}-5$ and $10 \mathrm{mg} / \mathrm{dm}^{3}$, respectively.

upwards with fixed rate of $0.15 \mathrm{dm}^{3} / \mathrm{min}$ [32]. The applied ozone dosage $\left(v_{\mathrm{Oz}}\right)$ was $0.8-2.0 \mathrm{mg} /\left(\mathrm{dm}^{3} \cdot \mathrm{min}\right)$ at constant flow rate of OAM $\left(0.07 \mathrm{dm}^{3} / \mathrm{min}\right)$ and the range of ozone concentration in OAM was $4.9-12.7 \mathrm{mg} / \mathrm{dm}^{3}$.

UV irradiation of solution or suspension was carried out by a low-pressure mercury-quartz lamp DB-15 ( $\lambda_{\max }=$ $254 \mathrm{~nm}$ ) located outside and parallel to the axis of the reactor at a distance of $5 \mathrm{~cm}$ from the wall. The UV radiation intensity $\left(I_{\mathrm{UV}}\right)$ entering the solution was $5.2 \mathrm{~mW} / \mathrm{cm}^{2}$.

The water of Dnieper River sampled in the winter and model solutions of FA were also treated in another reactor $(d$ $\left.=4.0 \mathrm{~cm}, V=0.36 \mathrm{dm}^{3}\right)$ [31] at higher applied ozone dosage and UV radiation intensity $\left(v_{\mathrm{oz}}=3.1-3.7 \mathrm{mg} /\left(\mathrm{dm}^{3} \cdot \mathrm{min}\right), I_{\mathrm{UV}}\right.$ about $\left.8 \mathrm{~mW} / \mathrm{cm}^{2}(\lambda=254 \mathrm{~nm})\right)$. In addition, river waters, sampled in the summer, were oxidized by $\mathrm{O}_{3} / \mathrm{UV}$ in the reactor $\left(V=0.625 \mathrm{dm}^{3}\right)$ with an immersed source of UV radiation (DRB-8) in the following parameters: $v_{\mathrm{oz}}=$ $1.9 \mathrm{mg} /\left(\mathrm{dm}^{3} \cdot \min \right), I_{\mathrm{UV}}=2.72 \mathrm{~mW} / \mathrm{cm}^{2}$, a thickness of layer irradiated $(l)-1.5 \mathrm{~cm}$, and a temperature of $27^{\circ} \mathrm{C}$.

After oxidation within 20-30 min the photocatalyst was separated from model solutions and river waters by centrifugation (8000 rpm).

Change in ABS concentration during oxidation was monitored by standard extraction-photometric method with methylene blue $(\mathrm{EPh})$ or advanced sorption-photometric $(\mathrm{SPh})$ technique with methylene blue (determination limit of $0.05 \mathrm{mg} / \mathrm{dm}^{3}$ and $0.02 \mathrm{mg} / \mathrm{dm}^{3}$, resp.) [8, 14]. The latter method allows to significantly improve the accuracy of the ASAS control in waters with high content of the NOM. For example, sorption-photometric $(\mathrm{SPh})$ technique allowed to determine $\sim 80 \%$ of initial concentration $\left(C_{0}=0.14 \mathrm{mg} / \mathrm{dm}^{3}\right)$ of sodium dodecyl sulfate (SDS) in the lake water containing HA $\left(15.3 \mathrm{mg} / \mathrm{dm}^{3}\right)$ and FA $\left(33.5 \mathrm{mg} / \mathrm{dm}^{3}\right)$ after the sample storage during 14 days, whereas the SDS recovery by standard (EPh) technique declined with time of $\sim 30 \%$ [8].

The degree of destruction of HA, FA, and NOM was estimated in terms of the discoloration $\left(\Delta A_{364}\right)$ of model solutions or river waters and the variation of optical density in UV region $\left(A_{254}\right)$ specifying the decomposition of aromatic structure. Absorption spectra of river waters and model solutions were recorded using a spectrophotometer Shimadzu UV-2450. Change of total concentration of organic compounds in the reaction mixtures was evaluated by reduction of total organic carbon (TOC) concentration which was determined using a Shimadzu TOC-VCSN analyzer.

\section{Results and Discussion}

Previously, it was found [8] that the binding of ASAS to humic acids depends on the duration of their contact. Humic acids at a concentration of more than $5 \mathrm{mg} / \mathrm{dm}^{3}$ essentially associated ASAS through 7-14 days. Therefore, to assess the impact of HA on the degree of ABS degradation, model solutions containing $\mathrm{ABS}$ and HA simultaneously $\left(C_{\mathrm{ABS}}=5 \mathrm{mg} / \mathrm{dm}^{3}\right.$, $C_{\mathrm{HA}}=10 \mathrm{mg} / \mathrm{dm}^{3}, \mathrm{pH} 7.2$ ) were oxidized by various methods directly after preparation and after a prolonged (14 days) storage.

Analysis of the data (Table 2) shows that the presence of HA in a fresh prepared model solution at a ratio of $\mathrm{TOC}_{\mathrm{HA}} / \mathrm{TOC}_{\mathrm{ABS}} \sim 1$ did not influenced the degree of photocatalytic transformation of ABS by ozone or oxygen and values of specific ozone consumption (i.e., absorbed ozone dose needed to reduce ABS concentration at $1 \mathrm{mg} / \mathrm{dm}^{3}$ ). Photocatalytic oxidation of fresh model solution by ozone or oxygen reduced the concentration of ABS by $94 \%-95 \%$ and 92\%-93\%, respectively, regardless of the concentrations of HA $\left(0\right.$ or $\left.10 \mathrm{mg} / \mathrm{dm}^{3}\right)$.

Residual concentration of ABS and specific ozone consumption increased slightly during photocatalytic oxidation of model solution containing ABS and HA after prolonged (14 days) storage (see Table 2). However, residual concentration of ABS in all model solutions after photocatalytic oxidation 
TABLE 2: Effect of humic acid on reduction of ABS concentration and values of specific ozone consumption under oxidation of model solutions by various methods.

\begin{tabular}{|c|c|c|c|c|c|c|c|}
\hline \multirow{2}{*}{ The content of model solution } & \multirow{2}{*}{ Oxidation method } & \multicolumn{2}{|c|}{$C_{\mathrm{ABS}}, \mathrm{mg} / \mathrm{dm}^{3}$} & \multicolumn{2}{|c|}{$\Delta C_{\mathrm{ABS}}, \%$} & \multicolumn{2}{|c|}{$D_{\mathrm{oz}} / \Delta C_{\mathrm{ABS}}, \mathrm{mg} / \mathrm{mg}$} \\
\hline & & $\mathrm{EPh}$ & $\mathrm{SPh}$ & $\mathrm{EPh}$ & $\mathrm{SPh}$ & $\mathrm{EPh}$ & $\mathrm{SPh}$ \\
\hline \multirow{5}{*}{$\mathrm{ABS}\left(C_{0}-5 \mathrm{mg} / \mathrm{dm}^{3}\right)$} & - & 5.43 & 5.06 & - & - & - & - \\
\hline & $\mathrm{O}_{3}$ & 4.35 & 4.45 & 20 & 25 & 2.4 & 4.3 \\
\hline & $\mathrm{O}_{3} / \mathrm{UV}$ & 0.68 & 0.64 & 87 & 87 & 2.5 & 2.7 \\
\hline & $\mathrm{O}_{3} / \mathrm{TiO}_{2} / \mathrm{UV}$ & 0.34 & 0.27 & 94 & 95 & 2.0 & 2.1 \\
\hline & $\mathrm{O}_{2} / \mathrm{TiO}_{2} / \mathrm{UV}$ & 0.49 & 0.41 & 91 & 92 & - & - \\
\hline \multirow{5}{*}{$\begin{array}{l}\text { ABS }\left(C_{0}-5 \mathrm{mg} / \mathrm{dm}^{3}\right) \\
+\mathrm{HA}\left(C_{0}-10 \mathrm{mg} / \mathrm{dm}^{3}\right) \\
(\text { fresh) }\end{array}$} & - & 4.90 & 5.20 & - & - & - & - \\
\hline & $\mathrm{O}_{3}$ & 3.35 & 3.45 & 32 & 34 & 5.2 & 4.6 \\
\hline & $\mathrm{O}_{3} / \mathrm{UV}$ & 0.60 & 0.75 & 88 & 86 & 2.7 & 2.6 \\
\hline & $\mathrm{O}_{3} / \mathrm{TiO}_{2} / \mathrm{UV}$ & 0.40 & 0.29 & 92 & 94 & 2.2 & 2.0 \\
\hline & $\mathrm{O}_{2} / \mathrm{TiO}_{2} / \mathrm{UV}$ & 0.55 & 0.36 & 89 & 93 & - & - \\
\hline \multirow{5}{*}{$\begin{array}{l}\text { ABS }\left(C_{0}-5 \mathrm{mg} / \mathrm{dm}^{3}\right) \\
+\mathrm{HA}\left(C_{0}-10 \mathrm{mg} / \mathrm{dm}^{3}\right) \\
\text { (storage over } 14 \text { days) }\end{array}$} & - & 2.18 & 4.85 & - & - & - & - \\
\hline & $\mathrm{O}_{3}$ & 1.06 & 3.3 & 51 & 32 & 6.4 & 4.6 \\
\hline & $\mathrm{O}_{3} / \mathrm{UV}$ & 0.28 & 0.61 & 87 & 87 & 6.5 & 2.9 \\
\hline & $\mathrm{O}_{3} / \mathrm{TiO}_{2} / \mathrm{UV}$ & 0.46 & 0.48 & 79 & 90 & 6.6 & 2.6 \\
\hline & $\mathrm{O}_{2} / \mathrm{TiO}_{2} / \mathrm{UV}$ & 0.28 & 0.51 & 87 & 89 & - & - \\
\hline
\end{tabular}

Note: Duration of treatment $(t)-20 \mathrm{~min}, v_{\mathrm{oz}}=0.8 \mathrm{mg} /\left(\mathrm{dm}^{3} \cdot \mathrm{min}\right), I_{\mathrm{UV}}=5.2 \mathrm{~mW} / \mathrm{cm}^{2}, T=18 \pm 1^{\circ} \mathrm{C}$.

by ozone or oxygen did not exceed the MPC (MPC of ASAS $=0.5 \mathrm{mg} / \mathrm{dm}^{3}[4]$ ).

Residual concentration of $\mathrm{ABS}$ was slightly above the MPC after $\mathrm{O}_{3} / \mathrm{UV}$ treatment of three model solutions and significantly (7-9 times) higher than the MPC-after ozonation of them. Smaller residual ABS concentration (by $\sim 1 \mathrm{mg} / \mathrm{dm}^{3}$ ) in ozonated fresh prepared model solution containing ABS and HA simultaneously, as compared to that in ozonated net solution of ABS (see Table 2), apparently was due to the ability of HA at low concentrations to induce the formation of high reactive ${ }^{\circ} \mathrm{OH}$ radicals. As it is known rate constants of $\mathrm{ABS}$ interaction with ${ }^{\circ} \mathrm{OH}$ radicals are several orders of magnitude higher than those with $\mathrm{O}_{3}$ molecules [12].

Both techniques (EPh and $\mathrm{SPh}$ ) used for monitoring of residual ABS concentrations in the course of oxidation of fresh model solutions by various methods gave similar results (see Table 2). At the same time, it was shown that the correctness of ABS determination by standard extractionphotometric technique $(\mathrm{EPh})$ in the initial and ozonated model solutions, containing both ABS and HA after prolonged storage (14 days), significantly decreased and was 45\% and $32 \%$, respectively, compared with sorption-photometric technique (SPh) (see Table 2). Therefore, the use of a standard $(\mathrm{EPh})$ method for monitoring of ASAS concentration during oxidative treatment of natural waters with high content of HA can lead to inaccurate assessment of degree of ABS removal and errors in calculating of values of specific ozone consumption.

Maybe, correctness of ABS determination by standard extraction-photometric technique $(\mathrm{EPh})$ in ozonated model solution was reduced due to its insufficient discoloration and therefore incomplete destruction of the associates, formed by
HA and ABS, in contrast to solutions, oxidized photocatalytically by ozone or oxygen (Table 3 ).

Along with a maximum reduction of ABS concentration, photocatalytic ozonation also provided the highest degree of destruction (mineralization) of organic impurities in all model solutions (by $67 \%-74 \%$ in terms of TOC) at minimum values of specific ozone consumption compared with other oxidation processes studied in this research (see Table 3 ). A substantial degree of HA destruction (by $68 \%$ in terms of TOC) and some lesser degree of mineralization of organic impurities (by 51\%-57\% in terms of TOC) of three model solutions, containing ABS, were achieved by photocatalytic oxidation with oxygen. The degree of mineralization of organic impurity by ozonation and $\mathrm{O}_{3} / \mathrm{UV}$ treatment of model solutions was, respectively, 3.9-5.5 and 1.6-3.5 times lower than under photocatalytic ozonation.

Analysis of values of specific ozone consumption per $1 \mathrm{mg} / \mathrm{dm}^{3}$ of TOC degraded (see Table 3 ) indicates that the mineralization of HA under oxidation by ozone or $\mathrm{O}_{3} / \mathrm{UV}$ was lighter than that of ABS. For example, value of specific ozone consumption during $\mathrm{O}_{3} / \mathrm{UV}$ treatment of model solutions containing $\mathrm{HA}$ and $\mathrm{ABS}$ was higher than that during oxidation of HA solutions. On the contrary, almost equal values of specific ozone consumption were needed for the mineralization of $\mathrm{HA}$ and $\mathrm{ABS}$ with photocatalytic ozonation, which also somewhat decreased during oxidation of model solutions containing HA and ABS simultaneously. Perhaps, humic acids are the sensitizers of ABS photocatalytic destruction by ozone.

The use of photocatalyst $\left(\mathrm{TiO}_{2}\right)$ together with both $\mathrm{O}_{3}$ and UV radiation reduced values of specific ozone consumption needed for mineralization of HA and ABS in model solutions 1.5-4 times (see Table 3). 
TABLE 3: The degree of destruction of organic contaminants of model solutions containing ABS and HA under oxidation by various methods.

\begin{tabular}{|c|c|c|c|c|}
\hline The content of model solution & Oxidation method & Discoloration, \% & $\Delta \mathrm{TOC}, \%$ & $D_{\mathrm{oz}} / \triangle \mathrm{TOC}, \mathrm{mg} / \mathrm{mg}$ \\
\hline \multirow{4}{*}{$\begin{array}{l}\mathrm{ABS}\left(C_{0}-5 \mathrm{mg} / \mathrm{dm}^{3}\right)+\mathrm{HA}\left(C_{0}-10 \mathrm{mg} / \mathrm{dm}^{3}\right) \\
\text { (fresh) }\end{array}$} & $\mathrm{O}_{3}$ & 74 & 18 & 7.4 \\
\hline & $\mathrm{O}_{3} / \mathrm{UV}$ & 84 & 21 & 8.9 \\
\hline & $\mathrm{O}_{3} / \mathrm{TiO}_{2} / \mathrm{UV}$ & 84 & 70 & 2.3 \\
\hline & $\mathrm{O}_{2} / \mathrm{TiO}_{2} / \mathrm{UV}$ & 68 & 57 & - \\
\hline \multirow{4}{*}{$\begin{array}{l}\mathrm{ABS}\left(C_{0}-5 \mathrm{mg} / \mathrm{dm}^{3}\right)+\mathrm{HA}\left(C_{0}-10 \mathrm{mg} / \mathrm{dm}^{3}\right) \\
\text { (storage over } 14 \text { days) }\end{array}$} & $\mathrm{O}_{3}$ & 54 & 13 & 9.0 \\
\hline & $\mathrm{O}_{3} / \mathrm{UV}$ & 62 & 20 & 10.3 \\
\hline & $\mathrm{O}_{3} / \mathrm{TiO}_{2} / \mathrm{UV}$ & 75 & 71 & 2.6 \\
\hline & $\mathrm{O}_{2} / \mathrm{TiO}_{2} / \mathrm{UV}$ & 75 & 51 & - \\
\hline \multirow{4}{*}{$\operatorname{ABS}\left(C_{0}-5 \mathrm{mg} / \mathrm{dm}^{3}\right)$} & $\mathrm{O}_{3}$ & - & 0 & - \\
\hline & $\mathrm{O}_{3} / \mathrm{UV}$ & - & 25 & 13.4 \\
\hline & $\mathrm{O}_{3} / \mathrm{TiO}_{2} / \mathrm{UV}$ & - & 67 & 4.3 \\
\hline & $\mathrm{O}_{2} / \mathrm{TiO}_{2} / \mathrm{UV}$ & - & 53 & - \\
\hline \multirow{4}{*}{$\mathrm{HA}\left(C_{0}-10 \mathrm{mg} / \mathrm{dm}^{3}\right)$} & $\mathrm{O}_{3}$ & 65 & 16 & 14.5 \\
\hline & $\mathrm{O}_{3} / \mathrm{UV}$ & 69 & 47 & 6.1 \\
\hline & $\mathrm{O}_{3} / \mathrm{TiO}_{2} / \mathrm{UV}$ & 78 & 74 & 4.0 \\
\hline & $\mathrm{O}_{2} / \mathrm{TiO}_{2} / \mathrm{UV}$ & 74 & 68 & - \\
\hline
\end{tabular}

Note: $t=20 \mathrm{~min}, v_{\mathrm{oz}}=0.8 \mathrm{mg} /\left(\mathrm{dm}^{3} \cdot \min \right), I_{\mathrm{UV}}=5.2 \mathrm{~mW} / \mathrm{cm}^{2}, T=18 \pm 1^{\circ} \mathrm{C}$.

TABLE 4: Reduction of ABS concentration in the course of oxidation of its solutions in natural waters by various methods.

\begin{tabular}{|c|c|c|c|c|c|c|c|c|}
\hline \multirow{2}{*}{ Object of research } & \multirow{2}{*}{ Oxidation method } & \multirow{2}{*}{$t, \min$} & \multirow{2}{*}{$v_{\mathrm{oz}}, \mathrm{mg} /\left(\mathrm{dm}^{3} \cdot \min \right)$} & \multicolumn{2}{|c|}{$C_{\mathrm{ABS}}, \mathrm{mg} / \mathrm{dm}^{3}$} & \multicolumn{2}{|c|}{$\Delta C_{\mathrm{ABS}}, \%$} & \multirow{2}{*}{$\begin{array}{c}D_{\mathrm{oz}} / \Delta C_{\mathrm{ABS}}, \\
\mathrm{mg} / \mathrm{mg}\end{array}$} \\
\hline & & & & $\mathrm{EPh}$ & $\mathrm{SPh}$ & $\mathrm{EPh}$ & $\mathrm{SPh}$ & \\
\hline \multirow{4}{*}{$\begin{array}{l}\text { Solution of ABS in Desna River } \\
\text { water }\end{array}$} & - & 0 & - & 4.97 & - & - & - & - \\
\hline & $\mathrm{O}_{3} / \mathrm{UV}$ & 20 & 0.9 & 1.43 & - & 71 & - & 3.3 \\
\hline & $\mathrm{O}_{3} / \mathrm{TiO}_{2} / \mathrm{UV}$ & & 0.9 & 0.29 & - & 94 & - & 2.8 \\
\hline & $\mathrm{O}_{2} / \mathrm{TiO}_{2} / \mathrm{UV}$ & & - & 0.68 & - & 86 & - & - \\
\hline \multirow{6}{*}{$\begin{array}{l}\text { Solution of ABS in Dnieper River } \\
\text { water }\end{array}$} & - & $\mathbf{0}$ & - & 4.90 & 4.95 & - & - & - \\
\hline & $\mathrm{O}_{3}$ & & 1.6 & 3.60 & 3.65 & 27 & 26 & 19.1 \\
\hline & $\mathrm{O}_{3} / \mathrm{UV}$ & 30 & 1.3 & 0.85 & 0.90 & 83 & 82 & 5.5 \\
\hline & $\mathrm{O}_{3} / \mathrm{TiO}_{2} / \mathrm{UV}$ & & 1.3 & 0.26 & 0.26 & 95 & 95 & 5.3 \\
\hline & $\mathrm{O}_{2} / \mathrm{TiO}_{2} / \mathrm{UV}$ & & - & 0.55 & 0.60 & 89 & 88 & - \\
\hline & $\mathrm{O}_{2} / \mathrm{UV}$ & & - & 3.25 & 3.10 & 37 & 39 & - \\
\hline
\end{tabular}

Note: Initial ABS concentration- $5 \mathrm{mg} / \mathrm{dm}^{3}, T=20 \pm 1^{\circ} \mathrm{C}$.

Thus, the presence of humic acids at the ratio $\mathrm{TOC}_{\mathrm{HA}} / \mathrm{TOC}_{\mathrm{ABS}} \sim 1$ did not affect the reduction of $\mathrm{ABS}$ concentration up to MPC during photocatalytic oxidation of neutral model solutions by ozone and oxygen. The values of specific ozone consumption per $1 \mathrm{mg} / \mathrm{dm}^{3}$ of ABS or per $1 \mathrm{mg} / \mathrm{dm}^{3}$ of TOC obtained in this study were close to the values established earlier [32] at a higher (10 times) initial concentration of substrate $(2.3 \mathrm{mg} \mathrm{O} / 3 / \mathrm{mg} \mathrm{ABS}$ and $4.0 \mathrm{mg}$ $\mathrm{O}_{3} / \mathrm{mg}$ TOC).

Oxidation of solutions of ABS in the Dnieper and Desna River waters by various methods made it possible to assess the overall influence of the matrix of natural waters (NOM and mineral impurities) on efficiency of ASAS removal (Table 4). Mentioned model solutions are characterized by a higher concentration of concomitant organic impurities (ratio $\left.\mathrm{TOC}_{\mathrm{NOM}} / \mathrm{TOC}_{\mathrm{ABS}}=2.1-3.5\right)$ and contain more than
$3 \mathrm{mg}-\mathrm{eq} / \mathrm{dm}^{3}$ of bicarbonate ions, which are scavengers of 'OH radicals (see Table 1 ).

Efficiency of photocatalytic removal of ABS from the Desna River water by two methods $\left(\mathrm{O}_{3} / \mathrm{TiO}_{2} / \mathrm{UV}\right.$, $\mathrm{O}_{2} / \mathrm{TiO}_{2} / \mathrm{UV}$ ) (Table 4) was close to efficiency of its removing from fresh model solution containing $A B S$ and HA simultaneously at similar oxidation parameters (see Table 2), but value of specific ozone consumption increased. At the same time, $\mathrm{O}_{3} / \mathrm{UV}$ treatment of $\mathrm{ABS}$ solution in the Desna River water provided significantly less reduction of its concentration compared both with photocatalytic ozonation of mentioned solution and with $\mathrm{O}_{3} / \mathrm{UV}$ treatment of model solution containing ABS and HA simultaneously (by 23\% and 17\%, resp.) (see Tables 2 and 4).

Oxidation of ABS solution in the Dnieper River water was conducted at higher applied ozone dosage and prolonged 
TABLE 5: The degree of destruction of organic contaminants during oxidation of river waters and model ABS solutions in them by various methods.

\begin{tabular}{|c|c|c|c|c|c|c|}
\hline Water sample & Oxidation method & $t, \min$ & $v_{\mathrm{oz}}, \mathrm{mg} /\left(\mathrm{dm}^{3} \cdot \mathrm{min}\right)$ & Discoloration, $\%$ & $\triangle \mathrm{TOC}, \%$ & $D_{\mathrm{oz}} / \Delta \mathrm{TOC}, \mathrm{mg} / \mathrm{mg}$ \\
\hline \multirow{3}{*}{ Desna River (winter) } & $\mathrm{O}_{3} / \mathrm{UV}$ & 20 & 0.9 & 87 & 28 & 6.1 \\
\hline & $\mathrm{O}_{3} / \mathrm{TiO}_{2} / \mathrm{UV}$ & & 0.9 & 93 & 33 & 4.9 \\
\hline & $\mathrm{O}_{2} / \mathrm{TiO}_{2} / \mathrm{UV}$ & & - & 50 & 5 & - \\
\hline \multirow{3}{*}{$\begin{array}{l}\text { ABS solution in Desna } \\
\text { River water }\end{array}$} & $\mathrm{O}_{3} / \mathrm{UV}$ & 20 & 0.9 & 83 & 18 & 6.8 \\
\hline & $\mathrm{O}_{3} / \mathrm{TiO}_{2} / \mathrm{UV}$ & & 0.9 & 88 & 26 & 5.5 \\
\hline & $\mathrm{O}_{2} / \mathrm{TiO}_{2} / \mathrm{UV}$ & & - & 55 & 16 & - \\
\hline \multirow{5}{*}{ Dnieper River (winter) } & $\mathrm{O}_{3}$ & & 2.0 & 75 & 14 & 12.8 \\
\hline & $\mathrm{O}_{3} / \mathrm{UV}$ & 30 & 2.0 & 87 & 40 & 7.5 \\
\hline & $\mathrm{O}_{3} / \mathrm{TiO}_{2} / \mathrm{UV}$ & & 2.0 & 91 & 47 & 6.0 \\
\hline & $\mathrm{O}_{2} / \mathrm{TiO}_{2} / \mathrm{UV}$ & & - & 68 & 17 & - \\
\hline & $\mathrm{O}_{2} / \mathrm{UV}$ & & - & 114 & 4 & - \\
\hline \multirow{5}{*}{$\begin{array}{l}\text { ABS solution in Dnieper } \\
\text { River water }\end{array}$} & $\mathrm{O}_{3}$ & & 1.6 & 70 & 13 & 11.8 \\
\hline & $\mathrm{O}_{3} / \mathrm{UV}$ & 30 & 1.3 & 91 & 29 & 4.8 \\
\hline & $\mathrm{O}_{3} / \mathrm{TiO}_{2} / \mathrm{UV}$ & & 1.3 & 91 & 33 & 4.7 \\
\hline & $\mathrm{O}_{2} / \mathrm{TiO}_{2} / \mathrm{UV}$ & & - & 62 & 26 & - \\
\hline & $\mathrm{O}_{2} / \mathrm{UV}$ & & - & 108 & 2 & - \\
\hline \multirow{2}{*}{ Dnieper River (winter) } & $\mathrm{O}_{3} / \mathrm{TiO}_{2} / \mathrm{UV}^{*}$ & 30 & 3.7 & 97 & 70 & 7.9 \\
\hline & $\mathrm{O}_{2} / \mathrm{TiO}_{2} / \mathrm{UV}^{*}$ & & - & 74 & 27 & - \\
\hline Dnieper River (summer) & $\mathrm{O}_{3} / \mathrm{UV}^{* *}$ & 30 & 1.9 & 98 & 47 & 3.1 \\
\hline Desna River (summer) & $\mathrm{O}_{3} / \mathrm{UV}^{* *}$ & 30 & 1.9 & 97 & 53 & 3.2 \\
\hline
\end{tabular}

Note: ${ }^{*} I_{\mathrm{UV}}=8 \mathrm{~mW} / \mathrm{cm}^{2}$ (lamp DRB-15), ${ }^{* *} I_{\mathrm{UV}}=2.72 \mathrm{~mW} / \mathrm{cm}^{2}$ (lamp DRB-8).

contact time, due to higher concentration of NOM (see Table 1). At photocatalytic ozonation the concentration of ABS in the Dnieper River water was reduced by 95\% (below MPC) over $30 \mathrm{~min}$ (see Table 4). Photocatalytic oxidation by oxygen and $\mathrm{O}_{3} / \mathrm{UV}$ treatment also were quite effective $\left(\Delta C_{\mathrm{ABS}}\right.$ was equal $88 \%$ and $82 \%$ over $30 \mathrm{~min}$, resp.). Ozonation and UV irradiation, used separately, were inefficient to remove ABS from the Dnieper River water, its concentration was reduced only by less than $40 \%$ within 30 min (see Table 4 ).

It should be noted that since the $\mathrm{TOC}_{\mathrm{NOM}} / \mathrm{TOC}_{\mathrm{ABS}}$ ratio in river waters was 2-3.5 times higher compared with model solutions containing ABS and HA, values of specific ozone consumption per $1 \mathrm{mg} / \mathrm{dm}^{3}$ of ABS significantly increased in the course of oxidation of ABS solutions in rivers waters by all methods used in our research, but they were lowest during photocatalytic ozonation (see Tables 2 and 4).

Assessments of efficiency of ABS removal from the Dnieper River water by a variety of oxidative methods based on monitoring its residual concentrations by two techniques (EPh and $\mathrm{SPh}$ ) are almost equal. Fulvic acids are the dominant fraction of NOM in the Dnieper River water [28], these substances poorly affected the correctness of ASAS monitoring by standard technique [8].

River waters are poorly coloured during the winter season (see Table 1). Therefore, all methods of oxidation, except UV irradiation, ensured a satisfactory degree of discoloration of river waters and model solutions of ABS in them over 20-30 min (the residual colour value was above $15 \mathrm{grad}$ ) (Table 5). The UV irradiation of the Dnieper River water within 30 min enhanced the intensity of its colour. However, the degree of complete degradation of organic contaminants of river waters (the degree of TOC mineralization), due to the presence of $>3 \mathrm{mg}$-eq $/ \mathrm{dm}^{3}$ of bicarbonate ions, was much smaller compared to oxidation of model solutions of ABS and HA in distilled water (see Tables 3 and 5). The TOC content of the Dnieper and Desna River waters and ABS solutions in them in the course of photocatalytic ozonation, $\mathrm{O}_{3} / \mathrm{UV}$ treatment, and photocatalytic oxidation with oxygen within $20-30 \mathrm{~min}$ was reduced by $33 \%-47 \%$, $18 \%-40 \%$, and $5 \%-26 \%$, respectively (see Table 5). Efficiency of photocatalytic mineralization of NOM of the Dnieper River water was significantly enhanced (above 1.5 times) by increasing applied ozone dosage and UV radiation intensity. Thus, due to replacement of air oxygen by ozone, the degree of TOC removal in the course of photocatalytic oxidation of river waters was increased 2.6-6.6 times. Ozonation and UV irradiation, used separately, as expected, had little effect on NOM mineralization of river waters.

It should be noted a marked increase of values of specific ozone consumption, reducing concentrations of ABS below MPC in the Desna River water compared with those obtained when model solutions of ABS and HA were oxidized, and a significant increase of these parameters during oxidation of ABS solution in the Dnieper River water (see Tables 2 and 4). The values of specific ozone consumption per $1 \mathrm{mg} / \mathrm{dm}^{3}$ of TOC of natural waters also varied significantly (see Tables 3 and 5). Mentioned difference in the values of specific ozone consumption under oxidative treatment of the Desna and 
TABLE 6: Effect of bicarbonate ions on the degree of destruction of fulvic acid by various methods.

\begin{tabular}{lccccc}
\hline $\begin{array}{l}\text { Characteristic of fulvic acid } \\
\text { solution }\end{array}$ & Oxidation method & $v_{\mathrm{oz}}, \mathrm{mg} /\left(\mathrm{dm}^{3} \cdot \mathrm{min}\right)$ & Discoloration, $\%$ & $\Delta \mathrm{TOC}, \%$ & $D_{\mathrm{oz}} / \Delta \mathrm{TOC}, \mathrm{mg} / \mathrm{mg}$ \\
\hline $\mathrm{TOC}_{0}-16.4 \mathrm{mg} / \mathrm{dm}^{3}, \mathrm{pH} 8.2$, & $\mathrm{O}_{3} / \mathrm{UV}$ & 3.2 & 94 & 35 & 10.1 \\
$2 \mathrm{mg}-\mathrm{eq} / \mathrm{dm}^{3} \mathrm{HCO}_{3}^{-}$ & $\mathrm{O}_{3} / \mathrm{TiO}_{2} / \mathrm{UV}$ & 3.4 & 98 & 60 & 6.7 \\
\hline $\mathrm{O}_{2} / \mathrm{TiO}_{2} / \mathrm{UV}$ & $\mathrm{O}_{3} / \mathrm{UV}$ & - & 92 & 30 & - \\
$\mathrm{TOC}_{0}-15.8 \mathrm{mg} / \mathrm{dm}^{3}, \mathrm{pH} 6$, & $\mathrm{O}_{3} / \mathrm{TiO}_{2} / \mathrm{UV}$ & 3.2 & 86 & 51 & 7.3 \\
$0 \mathrm{mg}-\mathrm{eq} / \mathrm{dm}^{3} \mathrm{HCO}_{3}^{-}$ & $\mathrm{O}_{2} / \mathrm{TiO}_{2} / \mathrm{UV}$ & - & 94 & 55 & 4.6 \\
\hline
\end{tabular}

Note: $t=30 \mathrm{~min} ; I_{\mathrm{UV}}=8 \mathrm{~mW} / \mathrm{cm}^{2} ; T=18 \pm 1^{\circ} \mathrm{C}$.

Dnieper River waters (see Tables 4 and 5) appeared to have been caused by a change of both quantitative and qualitative contents of NOM in them. As it is known the composition of organic impurities of the river waters varies seasonally. In winter, the river waters contain more weakly coloured krenic acids which are resistant to oxidation, while in summer more intensely coloured and easily oxidizable apokrenic acids dominate in content of NOM [33]. As one can see from the Table 5, $\mathrm{O}_{3} / \mathrm{UV}$ treatment of the Dnieper and Desna River waters sampled in summer at $v_{\mathrm{oz}}=1.9 \mathrm{mg} /\left(\mathrm{dm}^{3} \cdot \mathrm{min}\right)$ and $I_{\mathrm{UV}}$ $=2.72 \mathrm{~mW} / \mathrm{cm}^{2}$ ensured a higher degree of mineralization of organic impurities with less values of specific ozone consumption compared with oxidation of water sampled during winter.

Effect of bicarbonate ions on the degree of NOM destruction illustrates the data obtained in the course of $\mathrm{O}_{3} / \mathrm{UV}$ treatment and photocatalytic oxidation $\left(\mathrm{O}_{3} / \mathrm{TiO}_{2} / \mathrm{UV}\right.$, $\mathrm{O}_{2} / \mathrm{TiO}_{2} / \mathrm{UV}$ ) of model solutions of fulvic acids separated from the Dnieper River water (Table 6). The degree of mineralization of fulvic acids in model water containing $2 \mathrm{mg}-\mathrm{eq} / \mathrm{dm}^{3} \quad \mathrm{HCO}_{3}{ }^{-}$ions was reduced by $1.4-1.8$ times, while the values of specific ozone consumption increased $1.4-1.5$ times.

\section{Conclusions}

Comparison of efficiency of destruction of anionic surfactant-sodium alkylbenzene sulfonate (ABS) in model aqueous solutions by various oxidation methods $\left(\mathrm{O}_{2} / \mathrm{UV}, \mathrm{O}_{3}\right.$, $\left.\mathrm{O}_{3} / \mathrm{UV}, \mathrm{O}_{2} / \mathrm{TiO}_{2} / \mathrm{UV}, \mathrm{O}_{3} / \mathrm{TiO}_{2} / \mathrm{UV}\right)$ showed that photocatalytic ozonation $\left(\mathrm{O}_{3} / \mathrm{TiO}_{2} / \mathrm{UV}\right)$ is the most effective method of $\mathrm{ABS}$ removal from waters containing $\mathrm{HA}$ or NOM and bicarbonate ions. ABS concentration $\left(C_{0}=5 \mathrm{mg} / \mathrm{dm}^{3}\right)$ during photocatalytic ozonation of all model solutions with a ratio $\mathrm{TOC}_{\mathrm{NOM}} / \mathrm{TOC}_{\mathrm{ABS}} \sim 1-3.5$ was reduced by $94 \%-95 \%$ over $20-$ $30 \mathrm{~min}$ to values not exceeding the MPC $\left(<0.5 \mathrm{mg} / \mathrm{dm}^{3}\right)$.

Along with a maximum reduction of ABS concentration photocatalytic ozonation also ensured the highest degree of mineralization of organic impurities of all model solutions and river waters compared with other oxidation processes investigated in this research at the lowest values of specific ozone consumption per $1 \mathrm{mg} / \mathrm{dm}^{3}$ of TOC.

Values of specific ozone consumption significantly depended on the qualitative and quantitative contents of concomitant organic impurities and concentration of bicarbonate ions.

The degree of mineralization of organic impurities can be significantly enhanced by changing the parameters of photocatalytic ozonation (applied ozone dosage and UV radiation intensity) at a constant treatment time.

$\mathrm{ABS}$ concentration was reduced quite effectively also during photocatalytic oxidation with air oxygen and $\mathrm{O}_{3} / \mathrm{UV}$ treatment of model solutions (by $86 \%-93 \%$ and $71 \%-87 \%$ within 20-30 min, resp.), but the degree of mineralization of organic impurities by specified methods was lower compared to photocatalytic ozonation.

Ozonation and UV irradiation, used separately, were inefficient methods for ABS degradation $(<40 \%)$ and for TOC removal $(<15 \%)$.

\section{Acknowledgment}

The authors express their sincere gratitude to their supervisor Professor V. V. Goncharuk for substantial support and very useful comments when discussing the results of this study.

\section{References}

[1] G.-G. Ying, "Fate, behavior and effects of surfactants and their degradation products in the environment," Environment International, vol. 32, no. 3, pp. 417-431, 2006.

[2] A. K. Mungray and P. Kumar, "Fate of linear alkylbenzene sulfonates in the environment: a review," International Biodeterioration and Biodegradation, vol. 63, no. 8, pp. 981-987, 2009.

[3] M. Yu. Antomonov and I. V. Mudryi, "Prognostication of anthropogenic chemical pollution of the Dnepr River," Hygiene and Sanitation, no. 6, pp. 15-17, 1996 (Russian).

[4] Sanitary Regulations and Standards for Protection of Surface Waters from Pollution (SanPiN No. 4830-88), USSR Health Ministry Publications, Moscow, Russia, 1988, (Russian).

[5] Y. Hirayama, H. Ikegami, M. Machida, and H. Tatsumoto, "Simple and rapid determination of linear alkylbenzene sulfonates by in-tube solid-phase microextraction coupled with liquid chromatography," Journal of Health Science, vol. 52, no. 3, pp. 228-236, 2006.

[6] P. Eichhorn, S. V. Rodrigues, W. Baumann, and T. P. Knepper, "Incomplete degradation of linear alkylbenzene sulfonate surfactants in Brazilian surface waters and pursuit of their polar metabolites in drinking waters," Science of the Total Environment, vol. 284, no. 1-3, pp. 123-134, 2002. 
[7] J. Lintelmann, A. Katayama, N. Kurihara, L. Shore, and A. Wenzel, "Endocrine disruptors in the environment: (IUPAC technical report)," Pure and Applied Chemistry, vol. 75, no. 5, pp. 631-681, 2003.

[8] S. A. Dolenko, E. Yu. Alekseenko, and N. F. Kushchevskaya, "The impact of water-soluble humic acids on extractionphotometric determination of anionic SAS with methylene blue in natural waters," Journal of Water Chemistry and Technology, vol. 33, no. 3, pp. 183-186, 2011.

[9] R. Vinken, A. Höllrigl-Rosta, B. Schmidt, A. Schäffer, and P. F.-X. Corvini, "Bioavailability of a nonylphenol isomer in dependence on the association to dissolved humic substances," Water Science and Technology, vol. 50, no. 5, pp. 277-283, 2004.

[10] M. M. Yee, T. Miyajima, and N. Takisawa, "Study of ionic surfactants binding to humic acid and fulvic acid by potentiometric titration and dynamic light scattering," Colloids and Surfaces A, vol. 347, no. 1-3, pp. 128-132, 2009.

[11] L. K. Koopal, T. P. Goloub, and T. A. Davis, "Binding of ionic surfactants to purified humic acid," Journal of Colloid and Interface Science, vol. 275, no. 2, pp. 360-367, 2004.

[12] J. Rivera-Utrilla, M. Sánchez-Polo, J. D. Méndez-Díaz, M. A. Ferro-García, and M. I. Bautista-Toledo, "Behavior of two different constituents of natural organic matter in the removal of sodium dodecylbenzenesulfonate by $\mathrm{O}_{3}$ and $\mathrm{O}_{3}$ based advanced oxidation processes," Journal of Colloid and Interface Science, vol. 325, no. 2, pp. 432-439, 2008.

[13] M. E. Lindsey and M. A. Tarr, "Inhibited hydroxyl radical degradation of aromatic hydrocarbons in the presence of dissolved fulvic acid," Water Research, vol. 34, no. 8, pp. 23852389, 2000.

[14] S. A. Dolenko, E. Yu. Alekseenko, and N. F. Kushchevskaya, "Determination of anionic surface-active substances in waters," Journal of Water Chemistry and Technology, vol. 32, no. 5, pp. 297-302, 2010.

[15] W. Song, V. Ravindran, and M. Pirbazari, "Process optimization using a kinetic model for the ultraviolet radiation-hydrogen peroxide decomposition of natural and synthetic organic compounds in groundwater," Chemical Engineering Science, vol. 63, no. 12, pp. 3249-3270, 2008.

[16] C. Lin and K.-S. Lin, "Photocatalytic oxidation of toxic organohalides with $\mathrm{TiO}_{2} / \mathrm{UV}$ : the effects of humic substances and organic mixtures," Chemosphere, vol. 66, no. 10, pp. 1872$1877,2007$.

[17] T. E. Doll and F. H. Frimmel, "Photocatalytic degradation of carbamazepine, clofibric acid and iomeprol with P25 and Hombikat UV100 in the presence of natural organic matter (NOM) and other organic water constituents," Water Research, vol. 39, no. 2-3, pp. 403-411, 2005.

[18] K. Kosaka, H. Yamada, H. Tsuno, Y. Shimizu, and S. Matsui, "The effects of dissolved organic matter on the decomposition of di-n-butyl phthalate by ozone/hydrogen peroxide process," Water Science and Technology, vol. 49, no. 4, pp. 57-62, 2004.

[19] A. Latifoglu and M. D. Gurol, "The effect of humic acids on nitrobenzene oxidation by ozonation and $\mathrm{O}_{3} / \mathrm{UV}$ processes," Water Research, vol. 37, no. 8, pp. 1879-1889, 2003.

[20] O. Mihas, N. Kalogerakis, and E. Psillakis, "Photolysis of 2,4dinitrotoluene in various water solutions: effect of dissolved species," Journal of Hazardous Materials, vol. 146, no. 3, pp. 535539, 2007.

[21] L. Zhou, Y. Ji, C. Zeng, Y. Zhang, Z. Wang, and X. Yang, "Aquatic photodegradation of sunscreen agent $p$-aminobenzoic acid in the presence of dissolved organic matter," Water Research, vol. 47, no. 1, pp. 153-162, 2013.

[22] P. M. Nagarnaik and B. Boulanger, "Advanced oxidation of alkylphenol ethoxylates in aqueous systems," Chemosphere, vol. 85, no. 5, pp. 854-860, 2011.

[23] L. Chen, H.-Y. Zhou, and Q.-Y. Deng, "Photolysis of nonylphenol ethoxylates: the determination of the degradation kinetics and the intermediate products," Chemosphere, vol. 68, no. 2, pp. 354-359, 2007.

[24] F. J. Benitez, J. L. Acero, F. J. Real, G. Roldan, and F. Casas, "Comparison of different chemical oxidation treatments for the removal of selected pharmaceuticals in water matrices," Chemical Engineering Journal, vol. 168, no. 3, pp. 1149-1156, 2011.

[25] W. Zhang, Y. Li, Y. Su, K. Mao, and Q. Wang, "Effect of water composition on $\mathrm{TiO}_{2}$ photocatalytic removal of endocrine disrupting compounds (EDCs) and estrogenic activity from secondary effluent," Journal of Hazardous Materials, vol. 215216, pp. 252-258, 2012.

[26] M. Martínez-Zapata, C. Aristizábal, and G. Peñuela, "Photodegradation of the endocrine-disrupting chemicals 4-nnonylphenol and triclosan by simulated solar UV irradiation in aqueous solutions with Fe(III) and in the absence/presence of humic acids," Journal of Photochemistry and Photobiology A, vol. 251, no. 1, pp. 41-49, 2013.

[27] A. Kerc, M. Bekbolet, and A. M. Saatci, "Effects of oxidative treatment techniques on molecular size distribution of humic acids," Water Science and Technology, vol. 49, no. 4, pp. 7-12, 2004.

[28] P. N. Linnik and T. A. Vasilchuk, "The role of humic substances in the processes of complexation and detoxication (by the example of the Dnieper reservoirs)," Hydrobiological Journal, vol. 38, no. 5, pp. 82-97, 2002.

[29] N. A. Klimenko, E. A. Samsoni-Todorova, L. A. Savchina, I. A. Lavrenchuk, and T. N. Zasyad'ko, "Seasonal variations of characteristics of organic matter in the Dnieper River water," Journal of Water Chemistry and Technology, vol. 34, no. 3, pp. 154-161, 2012.

[30] Yu. O. Shvadchina, V. F. Vakulenko, E. E. Levitskaya, and V. V. Goncharuk, "Photocatalytic destruction of anionic SAS with oxygen and hydrogen peroxide in the $\mathrm{TiO}_{2}$ suspension," Journal of Water Chemistry and Technology, vol. 34, no. 5, pp. 218-226, 2012.

[31] V. V. Goncharuk, V. F. Vakulenko, T. N. Sitnichenko, Yu. O. Shvadchina, and A. N. Sova, "Photocatalytic destruction of fulvic acids by ozone and oxygen," Journal of Water Chemistry and Technology, vol. 35, no. 2, pp. 62-70, 2013.

[32] Yu. O. Shvadchina, V. F. Vakulenko, A. N. Sova, and V. V. Goncharuk, "The photocatalytic degradation of anionic surfactants by ozone and oxygen," Journal of Water Chemistry and Technology, vol. 35, no. 5, pp. 351-365, 2013 (Russian).

[33] M. A. Shevchenko, P. V. Marchenko, P. N. Taran, and V. V. Lizunov, Oxidants in Technology of Water Treatment, Naukova Dumka Publications, Kiev, Ukraine, 1979, (Russian). 

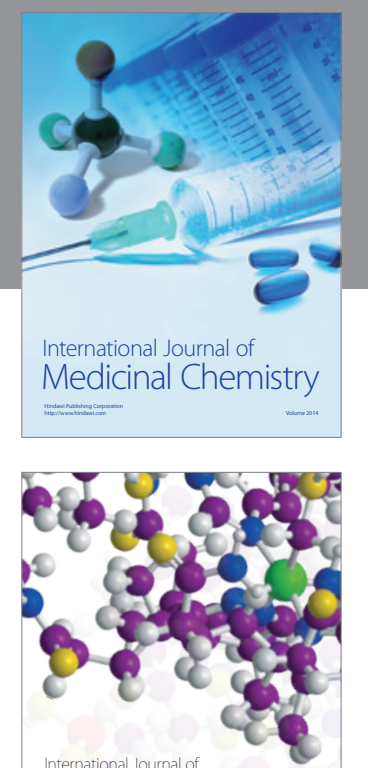

\section{Carbohydrate} Chemistry

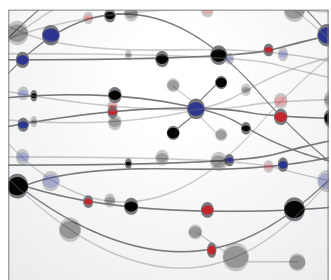

The Scientific World Journal
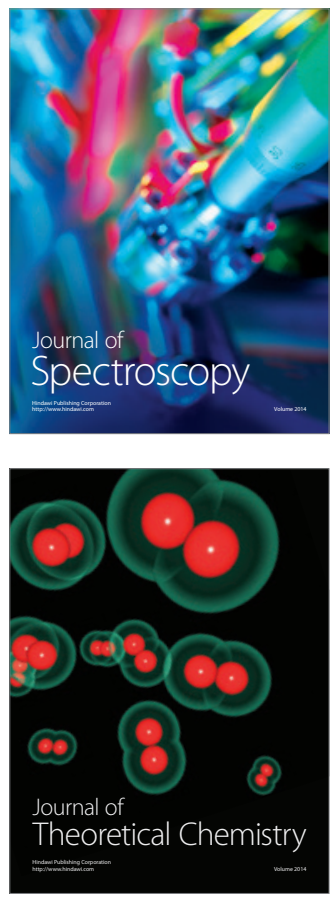
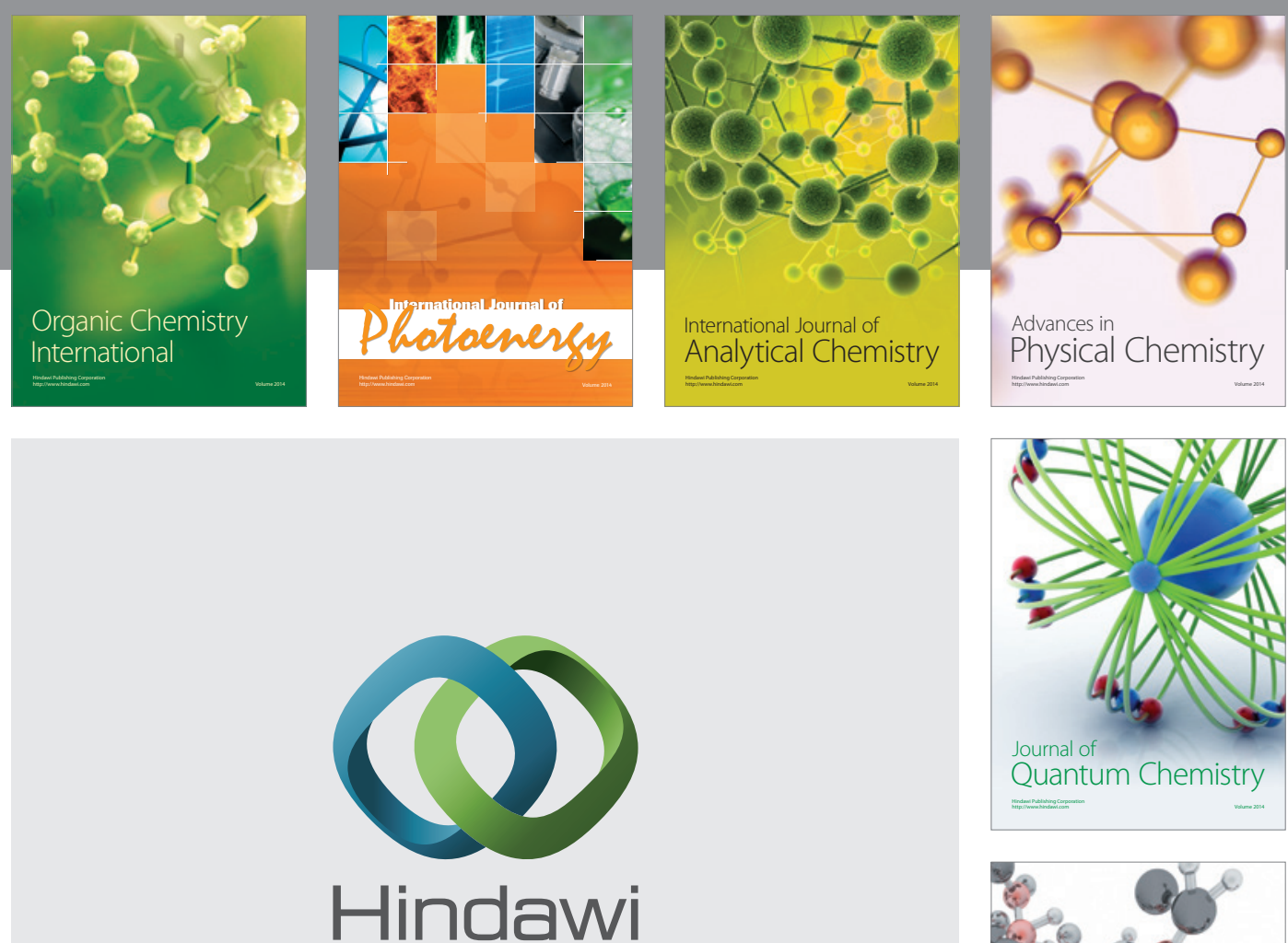

Submit your manuscripts at

http://www.hindawi.com

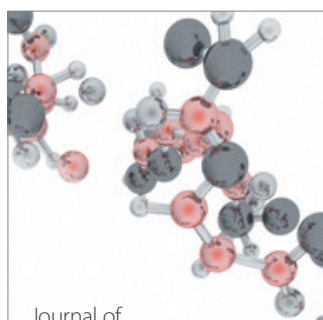

Analytical Methods

in Chemistry

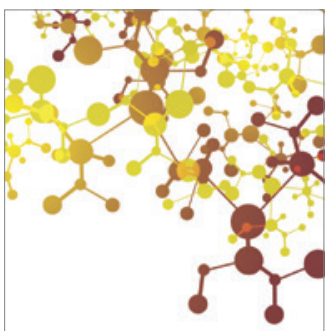

Journal of

Applied Chemistry

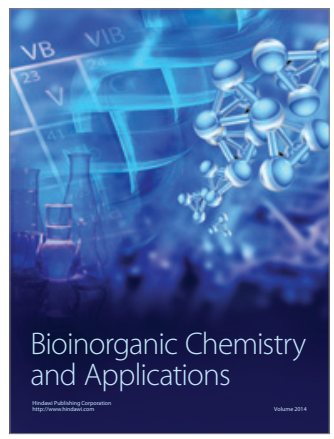

Inorganic Chemistry
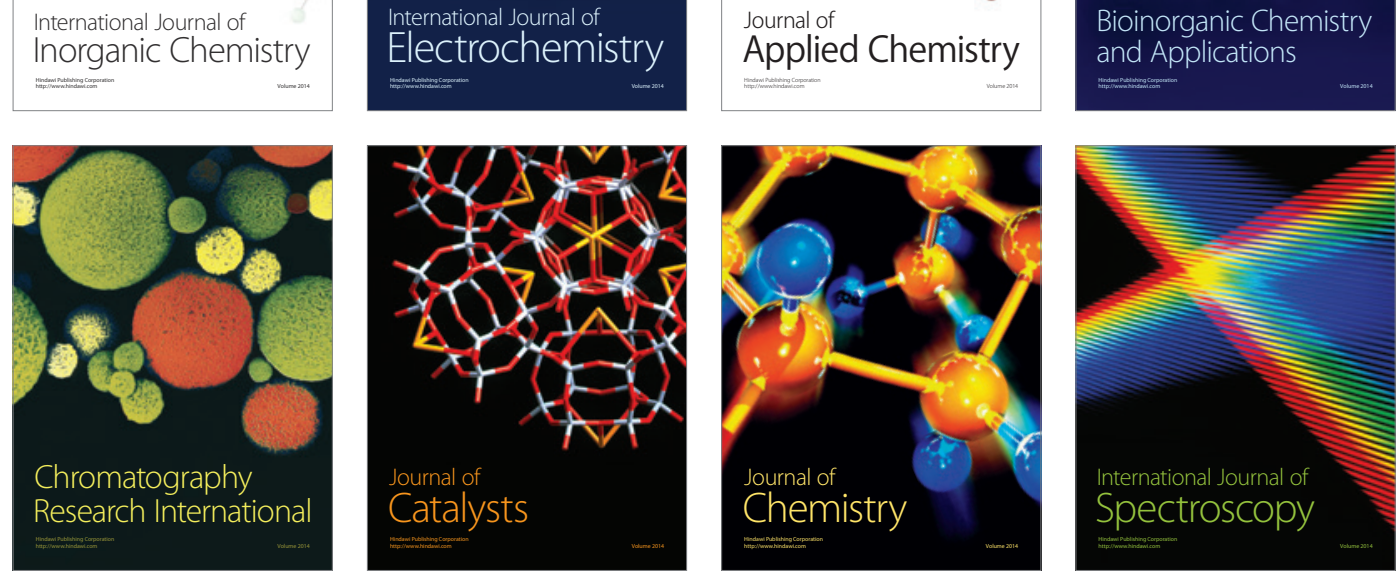